\title{
Moringin activates Wnt canonical pathway by inhibiting GSK3 $\beta$ in a mouse model of experimental autoimmune encephalomyelitis
}

This article was published in the following Dove Press journal:

Drug Design, Development and Therapy

4 October 2016

Number of times this article has been viewed

\author{
Sabrina Giacoppo' \\ Thangavelu Soundara Rajan' \\ Gina Rosalinda De Nicola ${ }^{2}$ \\ Renato lori ${ }^{2}$ \\ Placido Bramanti ${ }^{1}$ \\ Emanuela Mazzon' \\ 'IRCCS Centre Neurolesi "Bonino- \\ Pulejo”, Messina, Italy; ${ }^{2}$ Council for \\ Agricultural Research and Economics, \\ Research Centre for Industrial Crops \\ (CREA-CIN), Bologna, Italy
}

Correspondence: Emanuela Mazzon Pulejo", SSI I 3 Via Provinciale Palermo, Contrada Casazza, Messina 98124, Italy

Tel +3909060I2 8708

$\mathrm{Fax}+3909060128850$

Email emazzon.irccs@gmail.com IRCCS Centre Neurolesi "Bonino-

Abstract: Aberrant canonical Wnt- $\beta$-catenin signaling has been reported in multiple sclerosis (MS), although the results are controversial. The present study aimed to examine the role of the Wnt- $\beta$-catenin pathway in experimental MS and also to test moringin (4-[ $\alpha-\mathrm{L}-$ rhamnopyranosyloxy]-benzyl isothiocyanate), resulting from exogenous myrosinase hydrolysis of the natural phytochemical glucomoringin $4(\alpha$-L-rhamnosyloxy)-benzyl glucosinolate as a modulator of neuroinflammation via the $\beta$-catenin-PPAR $\gamma$ axis. Experimental autoimmune encephalomyelitis (EAE), the most common model of MS, was induced in C57BL/6 mice by immunization with $\mathrm{MOG}_{35-55}$. Released moringin ( $10 \mathrm{mg} / \mathrm{kg}$ glucomoringin $+5 \mu \mathrm{L}$ myrosinase/ mouse) was administered daily for 1 week before EAE induction and continued until mice were killed on day 28 after EAE induction. Our results clearly showed that the Wnt- $\beta$-catenin pathway was downregulated in the EAE model, whereas moringin pretreatment was able to avert this. Moringin pretreatment normalizes the aberrant Wnt- $\beta$-catenin pathway, resulting in GSK3 $\beta$ inhibition and $\beta$-catenin upregulation, which regulates T-cell activation (CD4 and FoxP3), suppresses the main inflammatory mediators (IL-1 $\beta$, IL-6, and COX2), through activation of PPAR $\gamma$. In addition, moringin attenuates apoptosis by reducing the expression of the Fas ligand and cleaved caspase 9, and in parallel increases antioxidant Nrf2 expression in EAE mice. Taken together, our results provide an interesting discovery in identifying moringin as a modulator of the Wnt- $\beta$-catenin signaling cascade and as a new potential therapeutic target for MS treatment.

Keywords: Wnt- $\beta$-catenin pathway, GSK3$\beta$, multiple sclerosis, moringin, PPAR $\gamma$, apoptosis

\section{Introduction}

The central logic of the Wnt- $\beta$-catenin-dependent or Wnt canonical pathway has been revealed in the past two decades. The Wnt-signaling pathway regulates many biological events occurring in the developmental and adult phases of all animals. ${ }^{1}$ Wnts are a family of secreted signaling proteins, which activate either $\beta$-catenin-dependent or -independent intracellular pathways by binding to the seven-pass transmembrane receptors of the Frizzled family. ${ }^{2}$ Generally, the Wnt1 class acts via the canonical pathway, while the Wnt5 class acts via the noncanonical pathway., ${ }^{3,4}$ The key role of the canonical Wnt pathway is the stabilization of $\beta$-catenin present in the cytoplasm. When the Wnt ligand is absent, $\beta$-catenin binds with the adenomatous polyposis coli-Axin complex, which promotes $\beta$-catenin phosphorylation via the GSK3 $\beta$ enzyme. Then, phosphorylated $\beta$-catenin binds with the ubiquitin complex, resulting in degradation. ${ }^{3,5}$ Wnt signaling prevents GSK3 $\beta$ activity, and thus increases the amount of $\beta$-catenin, which translocates into the nucleus and associates with TCF/LEF transcription factors, leading to the regulation of Wnt target genes. ${ }^{3}$ (c)
hereby accept the Terms. Non-commercial uses of the work are permitted without any further permission from Dove Medical Press Limited, provided the work is properly attributed. For permission for commercial use of this work, please see paragraphs 4.2 and 5 of our Terms (hintps:/wwww.doveperess.com/terms.php). 
Wnt- $\beta$-catenin signaling is involved in the development of sensory and motor neurons present in the brain and spinal cord via regulation of all facets of neuronal activities, including differentiation, proliferation/senescence, and survival/ apoptosis..$^{6-8}$ Moreover, Wnt-signaling pathway aberrations are associated with the adulthood diseases of the central nervous system (CNS), which points to its critical role in the development of the mature CNS. ${ }^{1,8}$ Growing evidence shows the importance of the Wnt- $\beta$-catenin pathway to stabilize neuronal cell survival and death in neurodegenerative diseases, such as Alzheimer's disease and Parkinson's disease. ${ }^{1,9-11}$ In addition, the Wnt- $\beta$-catenin pathway seems to be involved in the pathogenesis and modulation of chronic pain in experimental autoimmune encephalomyelitis (EAE) mice, ${ }^{12}$ the most commonly used model for multiple sclerosis (MS). However, the role of the Wnt canonical pathway in MS is still unclear.

MS is a chronic inflammatory disease caused by an induction of autoreactive immune responses effected from $\mathrm{T}$ and $\mathrm{B}$ lymphocytes, which results in the demyelination of the myelin sheath around neurons in the CNS. ${ }^{13,14}$ It is noteworthy to emphasize that the present-day treatments for MS provide palliative relief, but do not cure the disease. Moreover, these treatments trigger many side effects that hinder their application for a prolonged period. ${ }^{15}$ Therefore, new drugs that may act on the underlying etiology with no side effects are urgently required to treat MS.

In the last few decades, PPAR $\gamma$, an important target for diabetes treatment, ${ }^{16}$ has aroused great interest for its therapeutic role in brain disorders. ${ }^{17}$ In addition, since PPAR $\gamma$ is linked with the Wnt- $\beta$-catenin pathway, ${ }^{18,19}$ identifying novel PPAR $\gamma$ activators through Wnt- $\beta$-catenin pathway regulation has become a promising therapeutic approach for brain diseases.

In this regard, we investigated moringin (4-[ $\alpha-\mathrm{L}-$ rhamnopyranosyloxy]-benzyl isothiocyanate) as a modulator of neuroinflammation via the $\beta$-catenin-PPAR $\gamma$ axis in an experimental model of MS. Moringin is released from the precursor 4-( $\alpha$-L-rhamnosyloxy)-benzyl glucosinolate (glucomoringin [GMG]), found predominantly in the seeds of Moringa oleifera, the most widely distributed plant of the Moringaceae family, by myrosinase ( $\beta$-thioglucoside glucohydrolase; EC 3.2.1.147)-catalyzed hydrolysis.

Moringin has recently been characterized and proven to possess a broad range of biological activities, including protective effects against neurodegenerative disorders and particularly MS. ${ }^{20,21}$ In the present study, we evaluated the regulatory role of moringin in the Wnt canonical pathway and PPAR $\gamma$ activation in a mouse EAE model.

\section{Materials and methods Isolation and purification of glucomor- ingin and myrosinase}

GMG was isolated from $M$. oleifera seeds (PKM2 cake powder; Indena India Pvt Ltd, Bangalore, India) in two sequential steps - anion-exchange and size-exclusion chromatography - according to previously reported methods. ${ }^{22,23}$ The PKM2 cake powder was treated with boiling $70 \%$ ethanol, in order to quickly deactivate the endogenous enzyme myrosinase. GMG was extracted at medium speed using an Ultra-Turrax homogenizer for 15 minutes, and the resulting homogenate was centrifuged at $17,700 \times g$ for 30 minutes. The isolation of GMG from the extract was carried out by one-step anion-exchange chromatography. ${ }^{24}$ The extract was loaded on a DEAE Sephadex A-25 (GE Healthcare UK Ltd, Little Chalfont, UK) anion-exchange column $(150 \times 26 \mathrm{~mm})$ conditioned with $25 \mathrm{mM}$ acetate buffer ( $\mathrm{pH}$ 5.6). After being washed with $1 \mathrm{~L}$ of distilled water, GMG was eluted with $500 \mathrm{~mL}$ of aqueous $\mathrm{K}_{2} \mathrm{SO}_{4}, 0.2 \mathrm{M}$. The eluate was concentrated to dryness using a rotary evaporator at $60^{\circ} \mathrm{C}-70^{\circ} \mathrm{C}$ under reduced pressure. Three subsequent extractions were carried out with $70-100 \mathrm{~mL}$ of boiling methanol. The alcoholic extract was then filtered and concentrated to $15 \%-20 \%$ of the initial volume. The solution was warmed and slowly added dropwise to $200 \mathrm{~mL}$ of absolute ethanol that had been previously cooled to $-20^{\circ} \mathrm{C}$. This led to the precipitation of a white powder. After centrifugation, the solid GMG (as potassium salt) was dried and sealed under vacuum to prevent moisture uptake by the highly hygroscopic solid. The purity of GMG was further improved by gel filtration performed using an XK 26/100 column packed with Sephadex G-10 (GE Healthcare UK Ltd) connected to a fast protein liquid chromatography (LC) system (AKTA; GE Healthcare UK Ltd). ${ }^{25}$

The mobile phase was water at a flow rate of $2 \mathrm{~mL} / \mathrm{min}$, and the eluate absorbance was monitored at $254 \mathrm{~nm}$. After the void volume was discarded, $5 \mathrm{~mL}$ fractions were collected and analyzed by high-performance LC (HPLC), and those containing GMG were pooled and freeze-dried. ${ }^{26}$ The purity was assayed by HPLC analysis of the desulfo-derivative according to the ISO $9167-1$ method, ${ }^{27}$ yielding approximately $99 \%$ based on peak area value and more than $95 \%$ on a weight basis, due to its high hygroscopic properties, ${ }^{28}$ determined by a calibration curve of standard desulfo-GMG available in our laboratory. The enzyme myrosinase was 
isolated from white mustard (Sinapis alba) seeds according to a reported method with some modifications. ${ }^{29}$

Briefly, the enzyme was extracted from white-mustard seeds with water and purified by affinity chromatography on Con A Sepharose (GE Healthcare UK Ltd). Then, the active fractions coming from affinity chromatography were pooled and dialyzed against $50 \mathrm{mM}$ phosphate buffer, $\mathrm{pH}$ 6.5, containing $0.15 \mathrm{M} \mathrm{NaCl}$. The dialyzed Myr solution was concentrated and loaded onto a prepacked Superdex 200 HiLoad 26/60 gel-filtration column (GE Healthcare UK Ltd) equilibrated with $50 \mathrm{mM}$ phosphate buffer, $\mathrm{pH} 6.5$, containing $0.15 \mathrm{M} \mathrm{NaCl}$ connected with the fast protein LC system. The active fractions were pooled and concentrated with Amicon stirred cell model 8400 using an ultrafiltration membrane at $30 \mathrm{kDa}$ molecular weight cutoff (EMD Millipore, Billerica, MA, USA). The stock solution used in the present study had a specific activity of $60 \mathrm{U} / \mathrm{mg}$ of soluble protein. Enzymatic activity was $32 \mathrm{U} / \mathrm{mL}$, and the solution was stored at $4^{\circ} \mathrm{C}$ in sterile saline solution at neutral $\mathrm{pH}$ until use. One myrosinase unit was defined as the amount of enzyme able to hydrolyze $1 \mu \mathrm{mol} / \mathrm{min}$ of sinigrin at $\mathrm{pH} 6.5$ and $37^{\circ} \mathrm{C} .^{30}$

\section{Enzyme bioactivation of glucomoringin}

GMG (1 $\mathrm{mg} / \mathrm{mL}$ ) was suspended in phosphate-buffered saline (PBS; pH 7.2), and enzyme bioactivation of the phytochemical compound was required for mouse treatment. The in situ action of myrosinase $(20 \mu \mathrm{L} / \mathrm{mL})$ for 15 minutes at $37^{\circ} \mathrm{C}$ allowed the delivery of moringin quickly. Moreover, the total conversion of pure GMG into moringin before animal administration was confirmed by HPLC analysis, as reported in our previous work. ${ }^{31}$

\section{Induction of experimental autoimmune encephalomyelitis}

This study was carried out in strict accordance with the recommendations in the guide for the care and use of laboratory animals of the National Institutes of Health. The protocol was approved by the Ministry of Health "General Direction of animal health and veterinary drugs" and this study was approved by "Animal Welfare Bodies" of IRCCS Centro Neurolesi Bonino-Pulejo, Messina, Italy. Particularly, animal care was in compliance with Italian regulations on the protection of animals used for experimental and other scientific purposes (D.lgs 26/2014). All efforts were made during experimental procedures, to minimize animal suffering and also to reduce the number of animal used. Male C57BL/6 mice (20-25 g) were anesthetized with an anesthetic cocktail consisting of tiletamine plus xylazine $(10 \mathrm{~mL} / \mathrm{kg}$ intraperitoneally). EAE was induced in mice using the peptide $\mathrm{MOG}_{35-55}$ (MEVGWYRSPFSRVVHLYRNGK, peak area by HPLC $\geq 95 \%$; AnaSpec Inc., Fremont, CA, USA), based on Paschalidis et al. ${ }^{32}$ Mice were subcutaneously injected with $300 \mu \mathrm{L} /$ flank of the suspension consisting of an equal volume of $300 \mu \mathrm{g}$ $\mathrm{MOG}_{35-55}$ in PBS and complete Freund's adjuvant consisting of $300 \mu \mathrm{g}$ heat-killed Mycobacterium tuberculosis H37Ra (BD, Franklin Lakes, NJ, USA). After $\mathrm{MOG}_{35-55}$ injection, the animals immediately received an intraperitoneal injection of $100 \mu \mathrm{L}$ Bordetella pertussis toxin $(500 \mathrm{ng} / 100 \mu \mathrm{L}$; Sigma-Aldrich Co., St Louis, MO, USA) and 48 hours later. EAE induction followed a sequence of progressive degeneration with visible signs, such as tail flaccidity and loss of hind-leg movement.

\section{Experimental design}

Mice were randomly separated into the following groups ( $\mathrm{n}=35$ total animals):

1. naïve group $(n=5)$ - mice without any injection, serving as controls.

2. moringin control group $(n=5)$ - mice not subjected to EAE induction, but injected with moringin $(10 \mathrm{mg} / \mathrm{kg}$ GMG $+5 \mu \mathrm{L}$ Myr/mouse), killed as controls of drug safety and tolerance.

3. Myr control group $(n=5)-$ mice not subjected to EAE damage, but only injected with Myr ( $5 \mu \mathrm{L}$ Myr/mouse) to evaluate possible side effects, including allergenic reactions after administration.

4. EAE group $(n=10)-$ mice receiving MOG injection.

5. EAE + moringin $(n=10)-M O G-i n j e c t e d$ mice administered with moringin $(10 \mathrm{mg} / \mathrm{kg} \mathrm{GMG}+5 \mu \mathrm{L}$ myrosinase/ mouse); moringin administered intraperitoneally daily for 1 week before EAE induction and continued daily after EAE induction until death.

After 28 days of EAE induction, mice were killed and spinal cord tissues collected and processed for further analyses.

\section{Clinical disease-score evaluation}

Mice showed initial signs of MS, including loss of tail tonus, hind-limb paralysis, and loss of body weight, after 14 days of EAE induction. Clinical neurological score was assessed according to a standardized scoring system: ${ }^{33} 0$, no visible signs; 1 , partial flaccid tail; 2, complete flaccid tail; 3, hind limb hypotonia; 4, partial hind-limb paralysis; 5 , complete hind-limb paralysis; and 6, moribund or dead animal. Mice with a clinical score $\geq 5$ were killed to avoid 
animal suffering. The following clinical disease parameters were assessed: incidence, day of onset of clinical signs, peak disease score, cumulative disease score (CDS), and mortality (Table 1). The first assessment of neurological disease score was measured on the day of EAE induction (day 0), and all subsequent assessments were performed every 48 hours until mice were killed. Days' difference in the disease parameter is reported compared to the day of EAE induction (day 0). Days are reported as mean \pm standard error of mean of all mice for each experimental set.

\section{Immunohistochemistry}

Spinal cord tissues removed from the cervical region were fixed in 10\% (w/v) PBS-buffered formaldehyde and embedded in paraffin. The tissues were cut into $7 \mu \mathrm{m}$ sections. After deparaffinization, tissues were incubated with $0.3 \%(\mathrm{v} / \mathrm{v})$ hydrogen peroxide in $60 \%(\mathrm{v} / \mathrm{v})$ methanol for 30 minutes to terminate endogenous peroxidase activity. Then, the tissue sections were blocked in $2 \%(\mathrm{v} / \mathrm{v})$ normal goat serum in PBS for 20 minutes at room temperature.

Tissue sections were incubated overnight with the following primary antibodies:

- anti-IL-1 $\beta$ polyclonal antibody (1:50 in PBS v/v; Santa Cruz Biotechnology Inc., Dallas, TX, USA)

- anti-IL-6 polyclonal antibody (1:100 in PBS v/v; Abcam, Cambridge, UK)

- anti-Fas-ligand polyclonal antibody (1:100 in PBS v/v; Abcam)

- anti-cleaved caspase-9 monoclonal antibody (1:200 in PBS v/v; Abcam)

- anti-CD4 polyclonal antibody (1:100 in PBS v/v; Santa Cruz Biotechnology Inc.)

- anti-FoxP3 monoclonal antibody (1:100 in PBS v/v; Santa Cruz Biotechnology Inc.).

To avoid endogenous cross-reactivity of biotin- or avidin-binding sites, tissue sections were blocked separately with biotin and avidin for 15 minutes. Tissue sections were rinsed with PBS and incubated with secondary antibody. Specific labeling was performed using a biotin-conjugated antirabbit IgG and avidin-biotin peroxidase complex
(VectaStain; Vector Laboratories, Burlingame, CA, USA). Then, the tissue sections were stained using a DAB peroxidase-substrate kit (Vector Laboratories), followed by hematoxylin counterstaining. In addition, tissue sections were incubated with either primary or secondary antibody to assess antibody specificity. In these cases, no positive staining was observed in the tissue sections, indicating that the immunoreactions were positive in all the experiments carried out. Immunohistochemical staining was evaluated using light microscopy (Leica DM 2000 combined with Leica ICC50 HD camera), and images were acquired by Leica Application Suite version 4.2.0 software.

\section{Western blot analysis}

Spinal cord tissues were homogenized in ice-cold extraction buffer consisting of $0.32 \mathrm{M}$ sucrose, $10 \mathrm{mM}$ Tris- $\mathrm{HCl}$ ( $\mathrm{pH}_{7.4}$ ), $5 \mathrm{mM} \mathrm{NaN}_{3}, 2 \mathrm{mM}$ ethylenediaminetetraacetic acid (EDTA), $1 \mathrm{mM}$ ethyleneglycoltetraacetic acid (EGTA), $50 \mathrm{mM} \mathrm{NaF}, 10 \mathrm{mM}$ 2-mercaptoethanol, and protease-inhibitor tablets (Hoffman-La Roche Ltd, Basel, Switzerland). The homogenates were kept on ice for 15 minutes, centrifuged $\left(1,000 \mathrm{~g}\right.$ for 10 minutes at $\left.4^{\circ} \mathrm{C}\right)$, and the supernatant removed to estimate cytosolic proteins. The pellets were resuspended in ice-cold lysis buffer consisting of $10 \mathrm{mM}$ Tris- $\mathrm{HCl}$ ( $\mathrm{pH} 7.4$ ), $150 \mathrm{mM} \mathrm{NaCl}, 1 \mathrm{mM}$ EDTA, $1 \mathrm{mM}$ EGTA, 1\% Triton X-100, and proteaseinhibitor tablets. The resuspended pellets were kept on ice for 10 minutes, centrifuged $(15,000 \times g$ for 30 minutes at $4^{\circ} \mathrm{C}$ ), and the supernatant removed to estimate nuclear proteins. Supernatants were preserved at $-80^{\circ} \mathrm{C}$ until use. The quantity of protein was calculated with protein-assay reagent (Bio-Rad Laboratories Inc., Hercules, CA, USA). Bovine serum albumin was used as the standard. Proteins $(30 \mu \mathrm{g})$ were resolved on sodium dodecyl sulfate polyacrylamide minigels ( $8 \%$ or $12 \%$ ) and transferred onto polyvinylidene difluoride membranes (Immobilon-P transfer membrane; EMD Millipore). After transfer, membranes were blocked with PBS containing 5\% nonfat dried milk (PBS-milk (PM)) for 1 hour at room temperature, and incubated for overnight at $4^{\circ} \mathrm{C}$ overnight with specific antibodies: Wnt1

Table I Clinical parameters of EAE

\begin{tabular}{|c|c|c|c|c|c|}
\hline Group & $\begin{array}{l}\text { Incidence } \\
(\%)\end{array}$ & $\begin{array}{l}\text { Day of disease onset } \\
\text { (mean } \pm S D)\end{array}$ & $\begin{array}{l}\text { Peak disease } \\
\text { (mean } \pm \text { SD) }\end{array}$ & $\begin{array}{l}\text { Cumulative disease } \\
\text { score (mean } \pm \text { SD) }\end{array}$ & Mortality \\
\hline $\mathrm{EAE}$ & 100 & $12.2 \pm 0.62$ & $3.72 \pm 0.3$ & $28.21 \pm 10.4$ & $0 / 10$ \\
\hline $\mathrm{EAE}+$ moringin & 100 & $14.3 \pm 0.5$ & $1.26 \pm 0.2 *$ & $7.91 \pm 1.07^{*}$ & $0 / 10$ \\
\hline Naïve & 0 & 0 & 0 & 0 & $0 / 5$ \\
\hline
\end{tabular}

Notes: $* P<0.005$ compared to EAE group. Incidence was calculated as the percentage of mice that displayed any clinical signs of disease. One-way multiple comparisons with Tukey's test were used to determine the statistical significance of differences. All data calculated from two experiments. Day of onset, first day mice showed clinical signs; peak of disease, maximum score observed between days 0 and 28; cumulative disease score, mean of sum of daily scores observed between days 0 and 28 .

Abbreviations: EAE, experimental autoimmune encephalomyelitis; SD, standard deviation. 
(1:250; Santa Cruz Biotechnology), $\beta$-catenin (1:500; Cell Signaling Technology, Danvers, MA, USA), CK2 $\alpha$ (1:250; Santa Cruz Biotechnology Inc.), GSK3 $\beta$ (1:250; Santa Cruz Biotechnology Inc.), p- $\beta$-catenin (1:500; Santa Cruz Biotechnology Inc.), PPAR $\gamma(1: 250$; Santa Cruz Biotechnology Inc.), COX2 (1:250; Santa Cruz Biotechnology Inc.), and Nrf2 (1:250; Santa Cruz Biotechnology Inc.). Then, membranes were washed in PBS and incubated with horseradish peroxidase-conjugated antimouse, -goat, or -rabbit IgG secondary antibody $(1: 2,000$; Santa Cruz Biotechnology Inc.) for 1 hour at room temperature. Membranes were stripped and reprobed with $\beta$-actin $(1: 1,000$; Santa Cruz Biotechnology Inc.) to confirm uniform protein loading. Protein bands were detected by an enhanced chemiluminescence system (Luminata Western; EMD Millipore), and images were taken by ChemiDoc ${ }^{\mathrm{TM}}$ MP (Bio-Rad Laboratories Inc.) and quantified for relative expression of proteins using Image J software.

\section{Statistical analysis}

Statistical analysis was performed using GraphPad Prism version 6.0 (GraphPad Software, Inc., La Jolla, CA, USA). The data were statistically analyzed by one-way analysis of variance and Bonferroni post hoc tests for multiple comparisons. A $P$-value $\leq 0.05$ was considered statistically significant. Data are reported as mean \pm standard error of mean of $n$ experiments.

\section{Results}

\section{Moringin ameliorates clinical disease score}

Clinical disease score was evaluated as a functional neurological parameter. EAE is a well-documented model of MS in the mouse and resembles the hallmarks of the disease, such as paralysis, loss of body weight, inflammation, demyelination in the CNS and blood-brain barrier leakage. ${ }^{34}$ In order to study the role of moringin obtained by myrosinase hydrolysis (Figure 1A) in regulating susceptibility to EAE, mice were

\section{A}
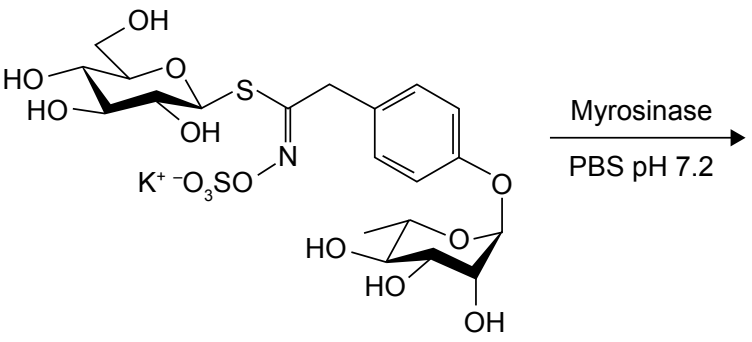

GMG

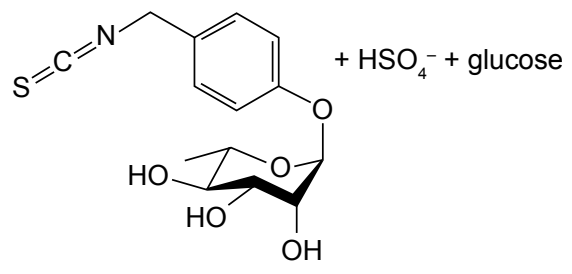

Moringin (GMG-ITC)

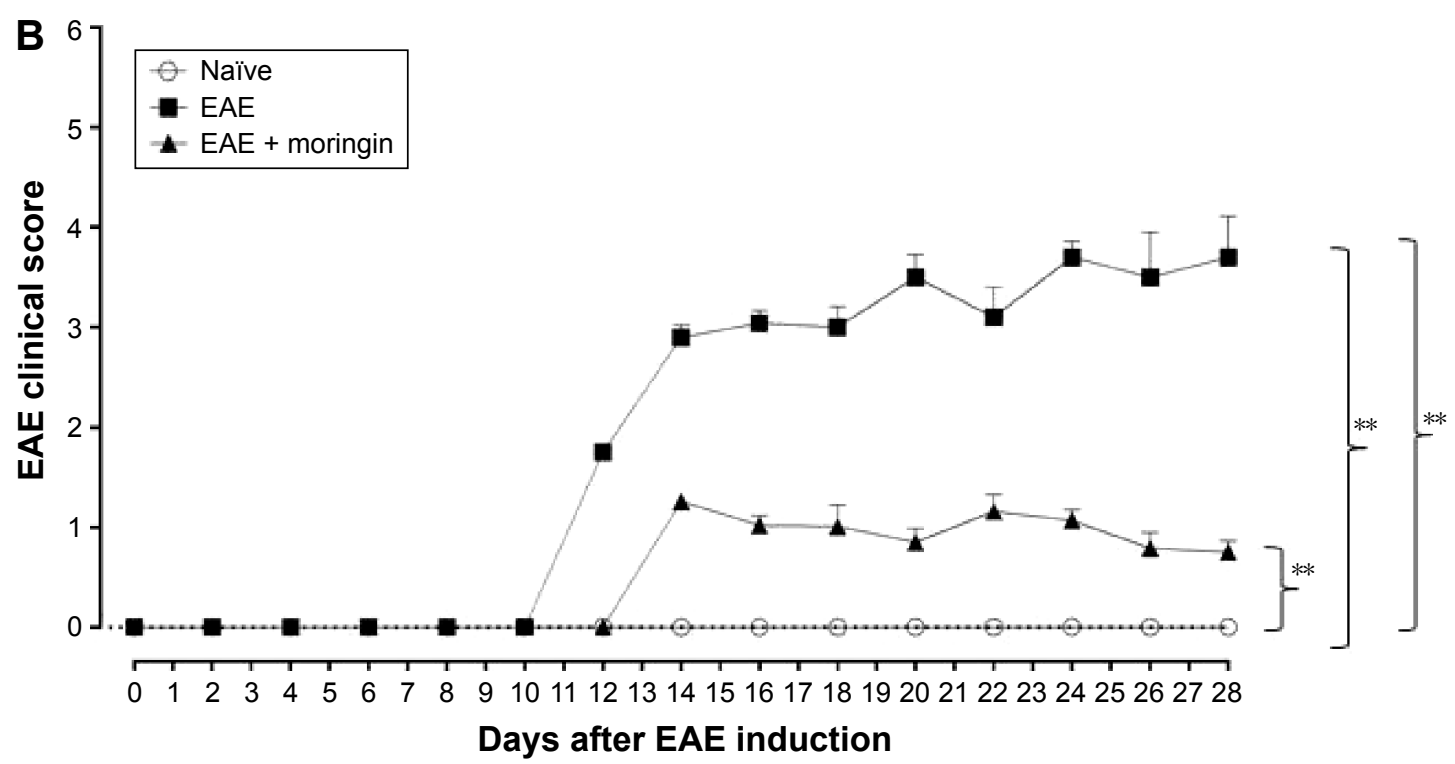

Figure I Treatment with moringin ameliorates clinical score in EAE mice.

Notes: (A) Chemical structure and enzymatic reaction for bioactivation of glucomoringin by myrosinase. (B) Clinical disease score. Scores expressed as mean \pm SEM of all measurements of each experimental group. Naïve group $(n=5)$, EAE group $(n=10)$, EAE + moringin $(n=10)$. Naïve vs $E A E$, *** $P=0.0018$; naïve vs $E A E+m o r i n g i n, * * P=0.005$; $E A E$ vs $E A E+$ moringin, $* * P=0.0019$. One way-analysis of variance with Bonferroni test were used to determine the statistical significance of differences. Data are expressed as mean \pm SEM.

Abbreviations: EAE, experimental autoimmune encephalomyelitis; SEM, standard error of mean; GMG, glucomoringin; ITC, isothiocyanate. 
pretreated with moringin and immunized with $\mathrm{MOG}_{35-55}$. The mice were monitored every 48 hours to assess clinical EAE signs. Compared to the EAE group, moringin pretreated mice showed a significant reduction in disease incidence and average CDS. The lower CDS in the EAE + moringin group was also reflected as a significant reduction in the severity of disease (Table 1). Indeed, EAE mice displayed a chronicprogressive clinical course, while significant reduction in clinical score was observed in EAE mice pretreated with moringin. No sign of motor deficits was noticed in naïve animals (Figure 1B). These results suggest that moringin reduces disease progression and increases recovery of neurological function in EAE mice.

\section{Moringin regulates the $\mathrm{Wnt}-\beta$-catenin signaling pathway in EAE development}

Western blot analysis was performed in order to observe the modulation of the Wnt- $\beta$-catenin signaling pathway after EAE induction in mouse spinal cord. Achieved results showed that the Wnt- $\beta$-catenin canonical pathway was downregulated in EAE mice. Lower Wnt1 expression (Figure 2A) was found in spinal cord tissues taken from EAE mice compared to naïve and control ones, which led to enhanced expression of GSK3 $\beta$ (Figure 2B), which acts synergistically with CK2 $\alpha$ (Figure 2C) in the multiprotein complex that phosphorylates cytoplasmic $\beta$-catenin, encouraging its ubiquitination and degradation. Indeed, $\beta$-catenin nuclear translocation was prevented in spinal cord tissues taken from EAE mice (Figure 2D), whereas cytoplasmic $\mathrm{p}$ - $\beta$-catenin expression was increased (Figure $2 \mathrm{E}$ ). On the contrary, moringin pretreatment positively regulated the Wnt- $\beta$-catenin signaling pathway in EAE mice. As demonstrated by Western blot analysis performed in spinal cord tissues, increased Wnt1 expression was found in pretreated EAE mice compared to untreated ones (Figure 2A). In addition, moringin pretreatment reduced the expression levels of GSK $3 \beta$ and CK2 $\alpha$ (Figure $2 \mathrm{~B}$ and $\mathrm{C}$ ), by inhibiting phosphorylation of cytoplasmic $\beta$-catenin (Figure 2D). These results were further corroborated by enhanced expression of $\beta$-catenin in the nucleus (Figure 2E).

\section{Moringin modulates apoptosis triggered by Wnt- $\beta$-catenin signaling pathway downregulation}

In order to investigate apoptosis, we studied Fas-ligand expression by immunohistochemistry in spinal cord sections. Results showed negative staining for Fas in naïve mice
(Figure 3A), moringin controls (Figure 3B), and Myr control mice (Figure 3C). On the contrary, marked immunopositivity for Fas in untreated EAE mice (Figure 3D, arrows) was found. Moringin-pretreated EAE mice showed negative staining for Fas (Figure 3E).

It is well known that activation of caspases is involved in apoptosis induction. Negative staining of cleaved caspase 9 was observed in naïve mice (Figure 4A), as well as in control groups (Figure 4B and C). Immunohistochemistry results also showed that cleaved caspase-9 level was considerably increased in EAE mice (Figure 4D). Moringin pretreatment totally suppressed the level of cleaved caspase 9 (Figure 4E).

\section{Moringin regulates production of CD4 and $\mathrm{T}_{\text {reg }}$ cells}

CD4 T-cell expression is involved in cell-mediated immunity and the pathogenesis of MS, with destruction of the axonal myelin sheath in several areas of the spinal cord mediated mainly by self-reactive CD4 T cells. Immunohistochemical analysis performed in spinal cord sections showed negative staining for CD4 in naïve (Figure 5A), moringin controls (Figure 5B), and Myr control mice (Figure 5C). Positive staining for CD4 was observed in EAE mice (Figure 5D); conversely, no positive staining for CD4 expression was obtained in mice pretreated with moringin (Figure 5E). In addition, in order to verify whether treatment with moringin could modulate the production of regulatory $\mathrm{T}\left(\mathrm{T}_{\mathrm{reg}}\right)$ cells, we evaluated expression of the transcription factor FoxP3 by immunohistochemical analysis. Our results showed negative staining for FoxP3 in naïve mice (Figure 6A) and in moringin, as well as the Myr control group (Figure 6B and C). Spinal cord sections from EAE mice showed positive staining for FoxP3 (Figure 6D), which was not observed in the tissues of EAE mice pretreated with moringin (Figure 6E).

\section{Moringin modulates neuroinflammation triggered by $\mathrm{Wnt}-\beta$-catenin signaling pathway downregulation}

Enhanced expression of proinflammatory cytokines has been associated with many neurodegenerative diseases, including MS. Furthermore, as it is known that Wnt- $\beta$-catenin signaling can regulate cytokine production, we analyzed the expression of IL-1 $\beta$ and IL-6 in spinal cord tissues collected from EAE-untreated and moringin-pretreated EAE mice by immunohistochemical staining.

As shown in Figure 7, no positive staining for IL-1 $\beta$ (Figure 7A) or IL-6 (Figure 8A) was obtained in naïve 

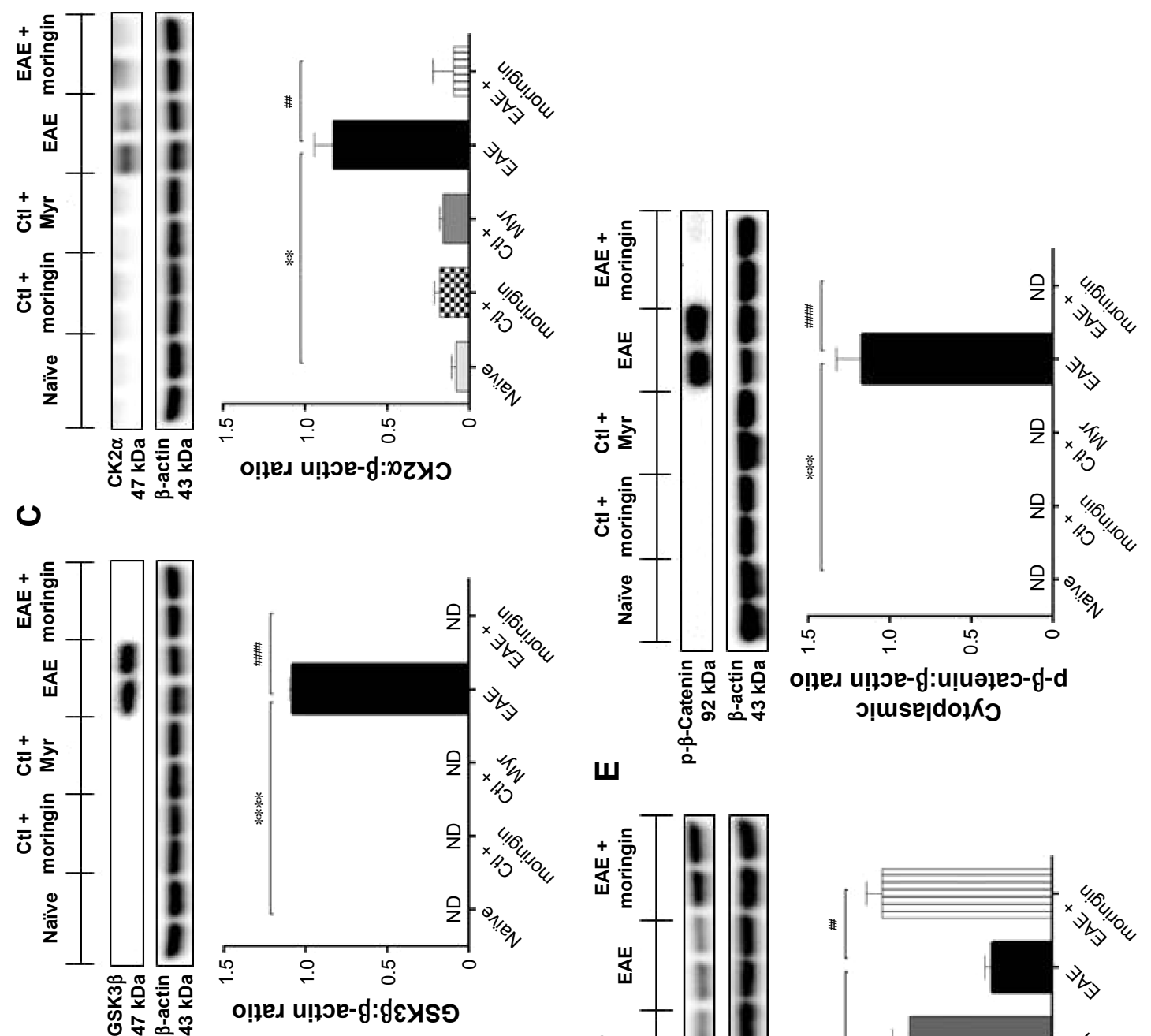

$\frac{n}{2}>0$

乙

岀主

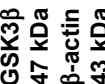

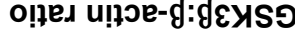

$\boldsymbol{m}$
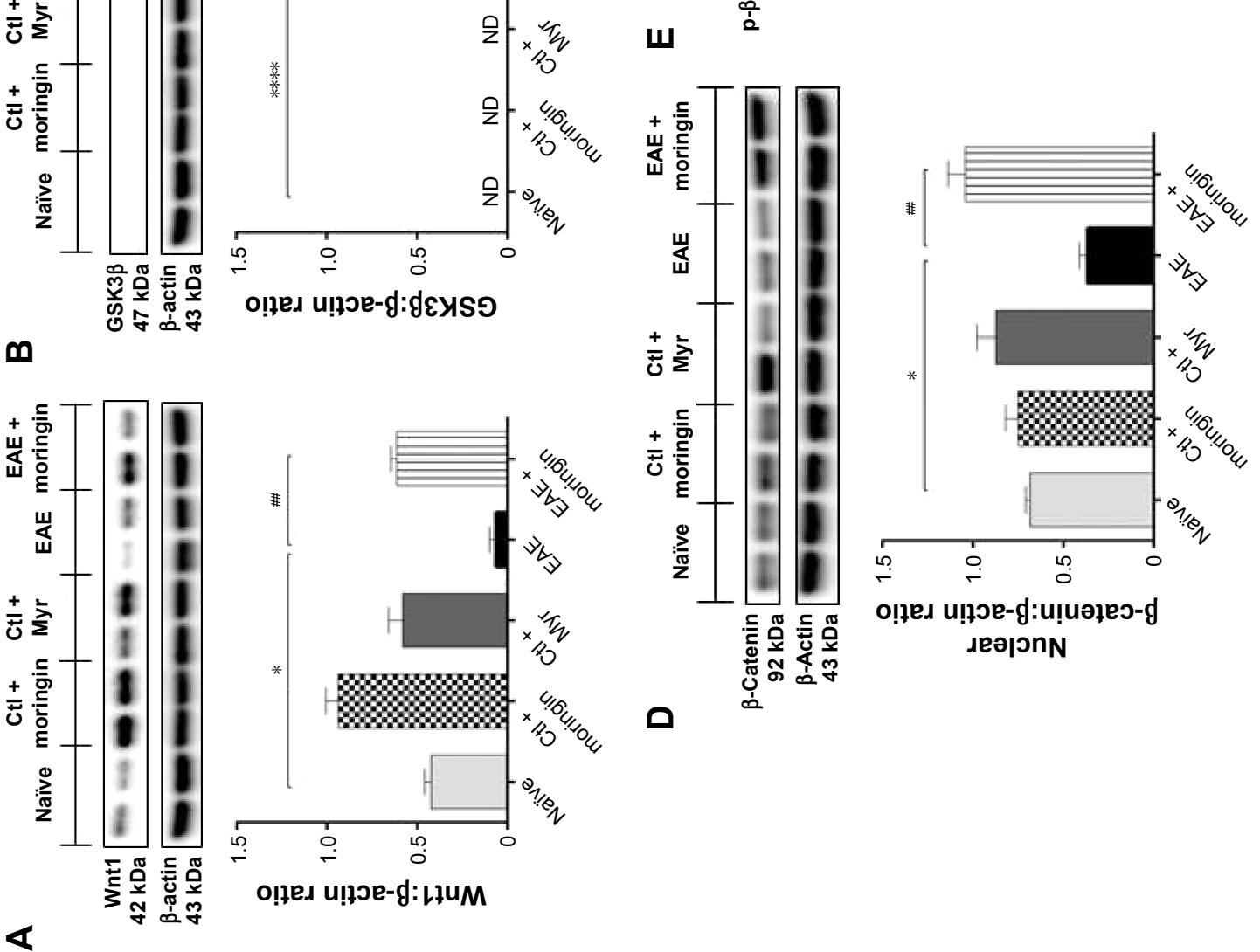

o!̣ed u!̣oe-d:u!̣uəłeว-g-d ग!Use|dołkว

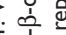

要

i 产

항

敦

它

岸了.

崖家总

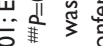

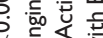

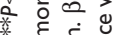

岸岩割

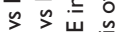

:

슨

लํํ त्रे

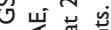

흐

늘

Z

응 0 .

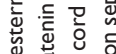

ऐ

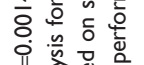

进热

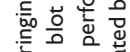

을

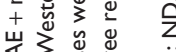

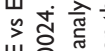

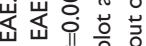

$\cong$ ô 菲

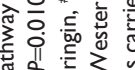

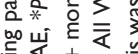

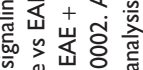

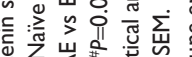

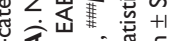

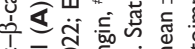

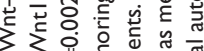

ज II E ह त

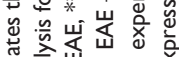

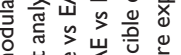

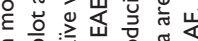

高

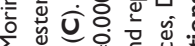

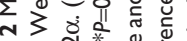

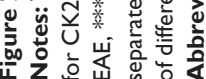




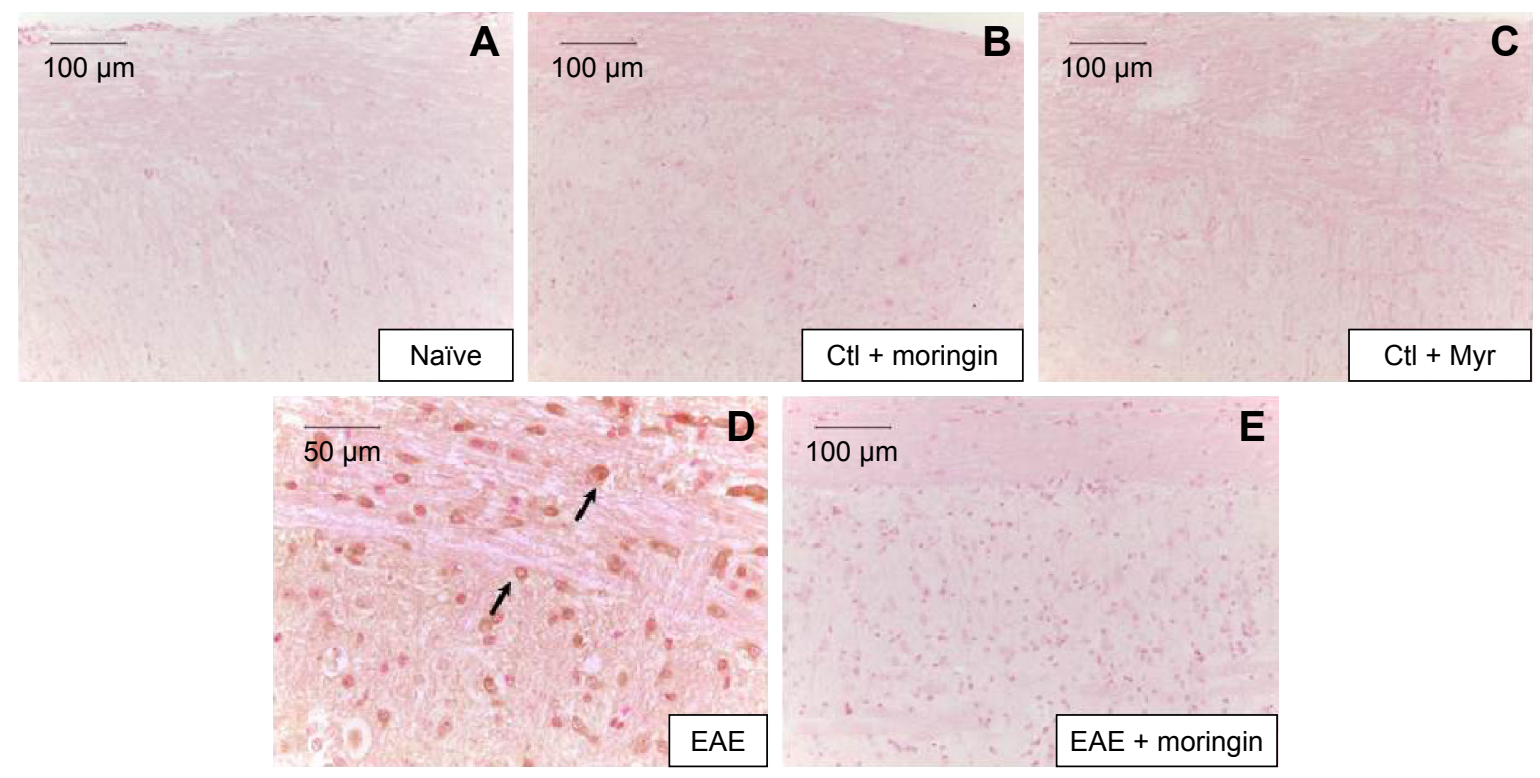

Figure 3 Moringin modulates Fas-ligand expression in EAE.

Notes: Immunohistochemical localization for Fas ligand in spinal cord tissues from naïve mice (A), Ctl + moringin (B), Ctl + Myr (C), EAE mice (D), and EAE mice pretreated with moringin (E). All images are representative of three independent experiments. The arrows indicate positive staining for FAs-ligand in cytoplasmic membranes of spinal cord tissues.

Abbreviations: EAE, experimental autoimmune encephalomyelitis; Ctl, control.

mice, in the moringin control group (Figures $7 \mathrm{~B}$ and $8 \mathrm{~B}$ ), or in Myr ones (Figures 7C and 8C), while high levels of the these proinflammatory mediators were noticed in spinal cord tissues of EAE mice. Specifically, positive inflammatory cells are indicated by arrows in spinal cord sections stained with IL-1 $\beta$ and IL-6 (Figures 7D and 8D, respectively) and arrowheads show vascular endothelium positive for IL-6 (Figure 8D). Negative staining for IL-1 $\beta$ and IL-6 was observed in spinal cord tissues from EAE mice pretreated with moringin (Figures $7 \mathrm{E}$ and $8 \mathrm{E}$, respectively). In addition, we investigated COX2 expression by Western blot analysis (Figure 9A). A basal level of COX2 was detected in naïve animals and control groups, while its level was significantly increased in EAE mice. Moringin-pretreated

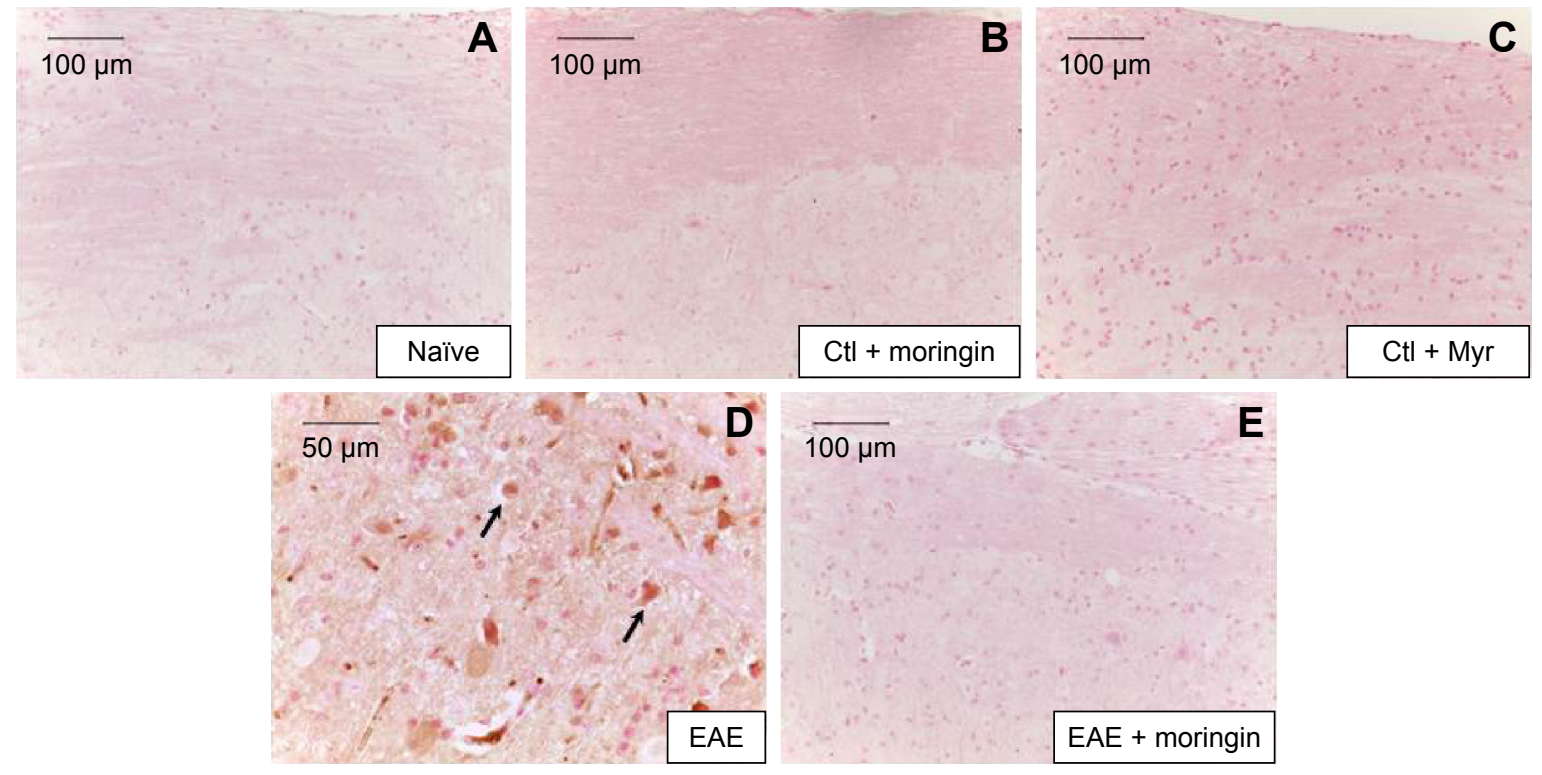

Figure 4 Moringin modulates cleaved caspase-9 expression in EAE.

Notes: Immunohistochemical localization for cleaved caspase 9 in naïve mice (A), Ctl + moringin (B), Ctl + Myr (C), EAE mice (D), and EAE mice pretreated with moringin (E). All images are representative of three independent experiments. The arrows indicate positive staining for cleaved caspase-9 in nuclei of spinal cord tissues. Abbreviations: EAE, experimental autoimmune encephalomyelitis; Ctl, control. 


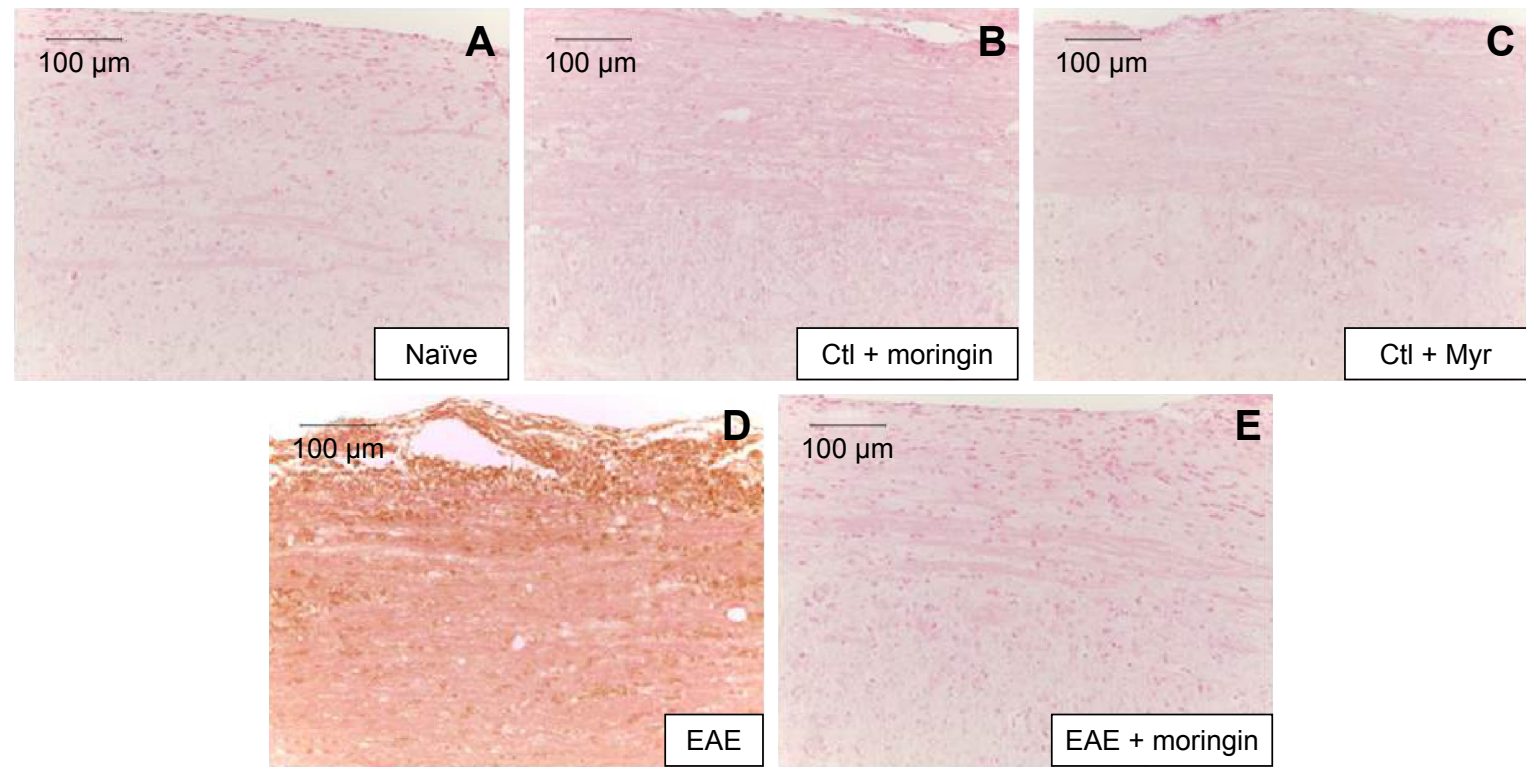

Figure 5 Moringin modulates CD4 expression in EAE.

Notes: Immunohistochemical evaluation for CD4 in naïve mice (A), Ctl + moringin (B), Ctl + Myr (C), EAE mice (D), and EAE mice pretreated with moringin (E). All images are representative of three independent experiments.

Abbreviations: EAE, experimental autoimmune encephalomyelitis; $\mathrm{Ctl}$, control.

EAE mice showed reduced COX2 expression. In addition, we investigated whether moringin could be a potential activator of PPAR $\gamma$ via Wnt- $\beta$-catenin signaling. By Western blot analysis, a mild increase in PPAR $\gamma$ expression was found in EAE mice, while administration of moringin markedly increased PPAR $\gamma$ levels. Neither naïve mice nor the Myr control group showed any expression for PPAR $\gamma$, whereas the moringin control group showed PPAR $\gamma$ expression (Figure 9B).

Moreover, as it is widely recognized that Glucosinolates (GLs) exert their protective effects by the capacity to induce expression of several enzymes via the Keap1-Nrf2-ARE pathway, ${ }^{35,36}$ we investigated expression of Nrf2. By Western blot analysis, we found that moringin pretreatment enhanced

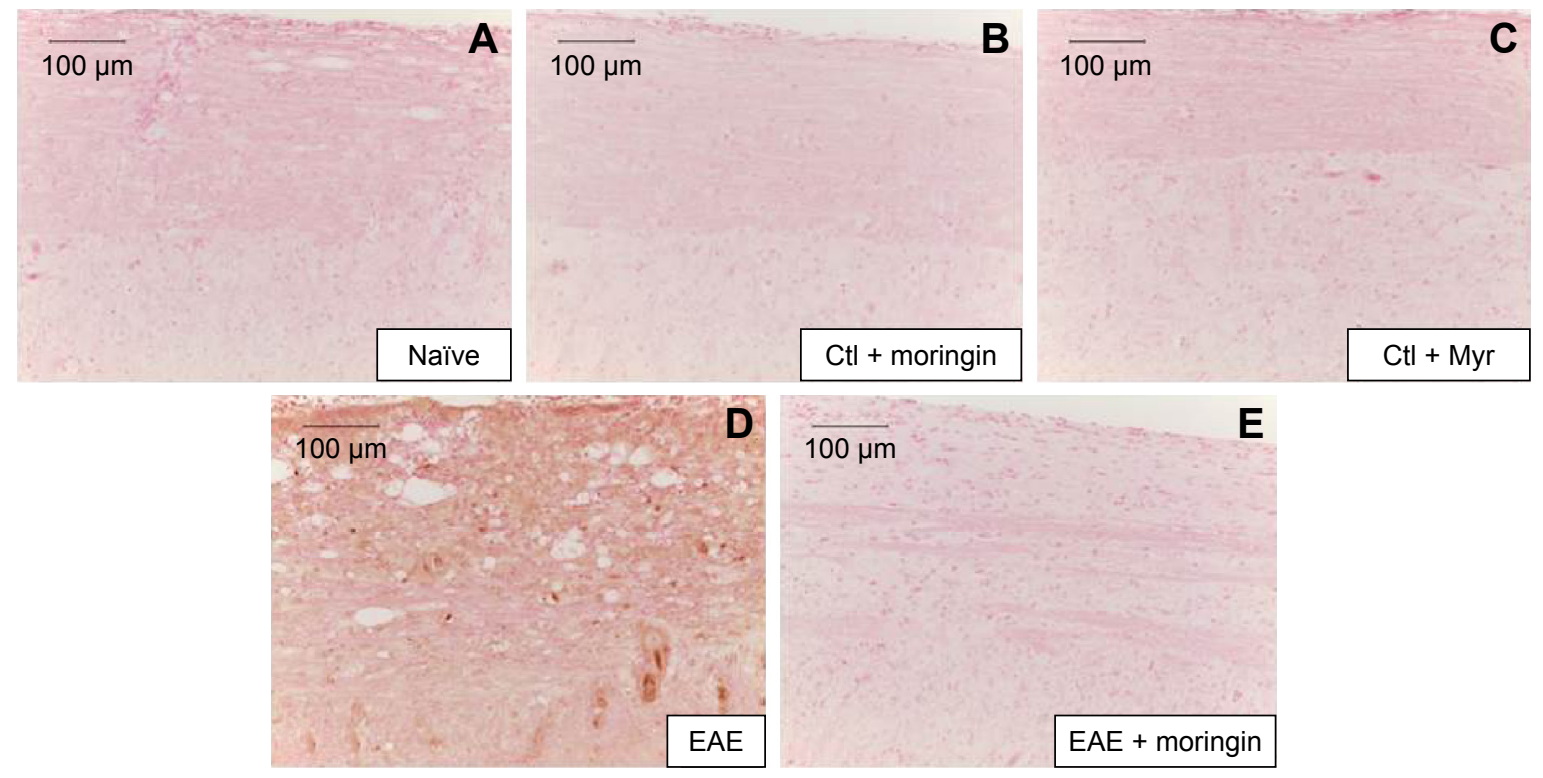

Figure 6 Moringin modulates FoxP3 expression in EAE.

Notes: Immunohistochemical evaluation for FoxP3-naïve mice (A), Ctl + moringin (B), Ctl + Myr (C), EAE mice (D), and EAE mice pretreated with moringin (E). All images are representative of three independent experiments.

Abbreviations: EAE, experimental autoimmune encephalomyelitis; $\mathrm{Ctl}$, control. 


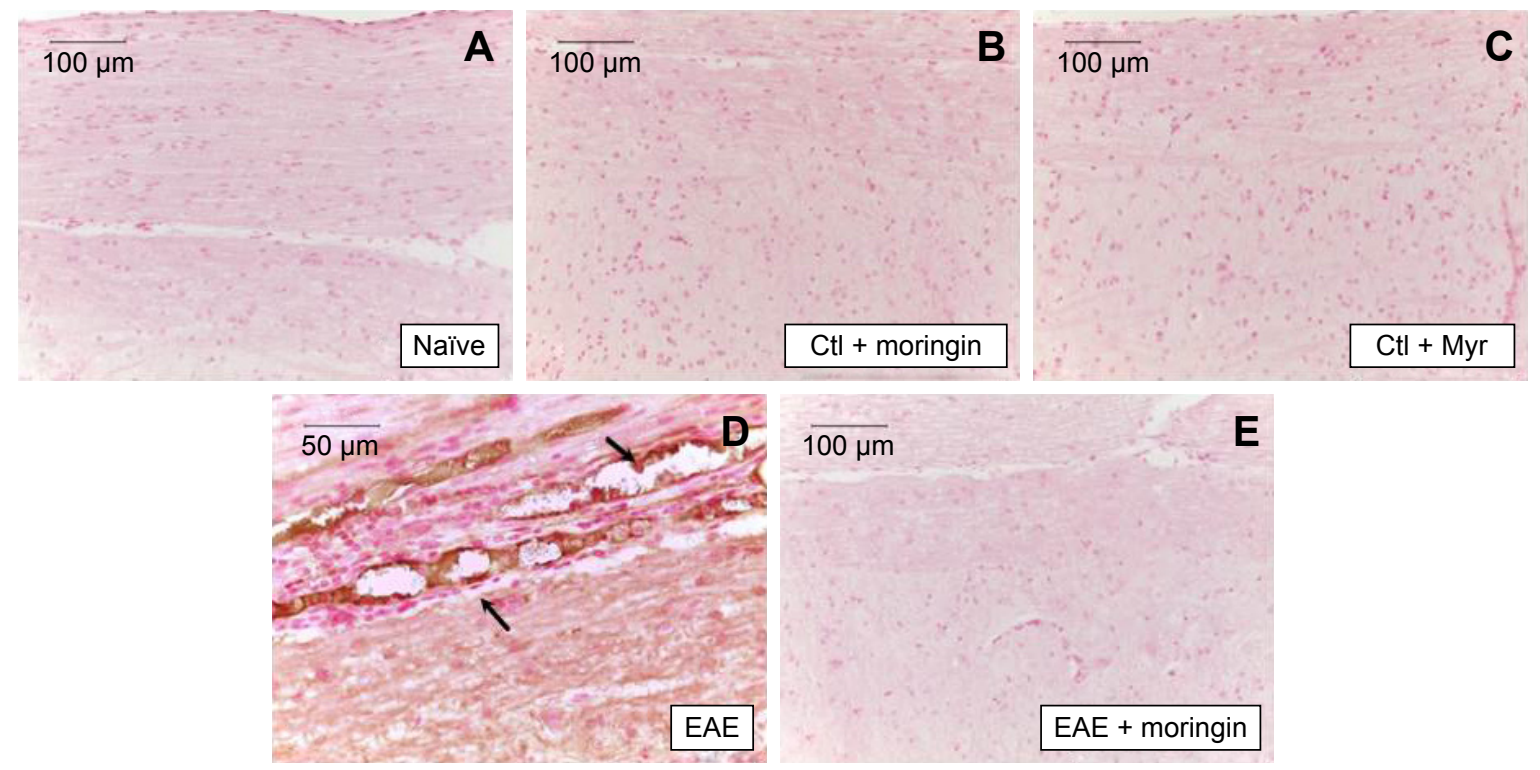

Figure 7 Moringin modulates IL-I $\beta$ expression in EAE.

Notes: Immunohistochemical localization for IL- I $\beta$ in spinal cord tissues from naïve mice (A), Ctl + moringin (B), Ctl + Myr (C), EAE mice (D), and EAE mice pretreated with moringin (E). All images are representative of three independent experiments. The arrows indicate positive staining for inflammatory cells in vascular endothelium of spinal cord tissues.

Abbreviations: EAE, experimental autoimmune encephalomyelitis; Ctl, control.

Nrf2 expression in EAE mouse spinal cord, while in untreated EAE mice, Nrf2 was absent (Figure 9C).

\section{Discussion}

MS is documented as the most common root of neurological disability. ${ }^{37}$ Recent research has described the importance of the Wnt- $\beta$-catenin signaling pathway for normal functioning of the adult CNS, and its aberration has been reported in degenerative and inflammatory CNS diseases, like MS. ${ }^{1,9,12,38,39}$ Moreover, Wnt signaling has been reported in immune cells present in the CNS, such as macrophages, microglia, and astrocytes, suggesting the critical role of the Wnt pathway in inflammation-mediated CNS injury and recovery. ${ }^{40,41}$ Although it is well known that the Wnt

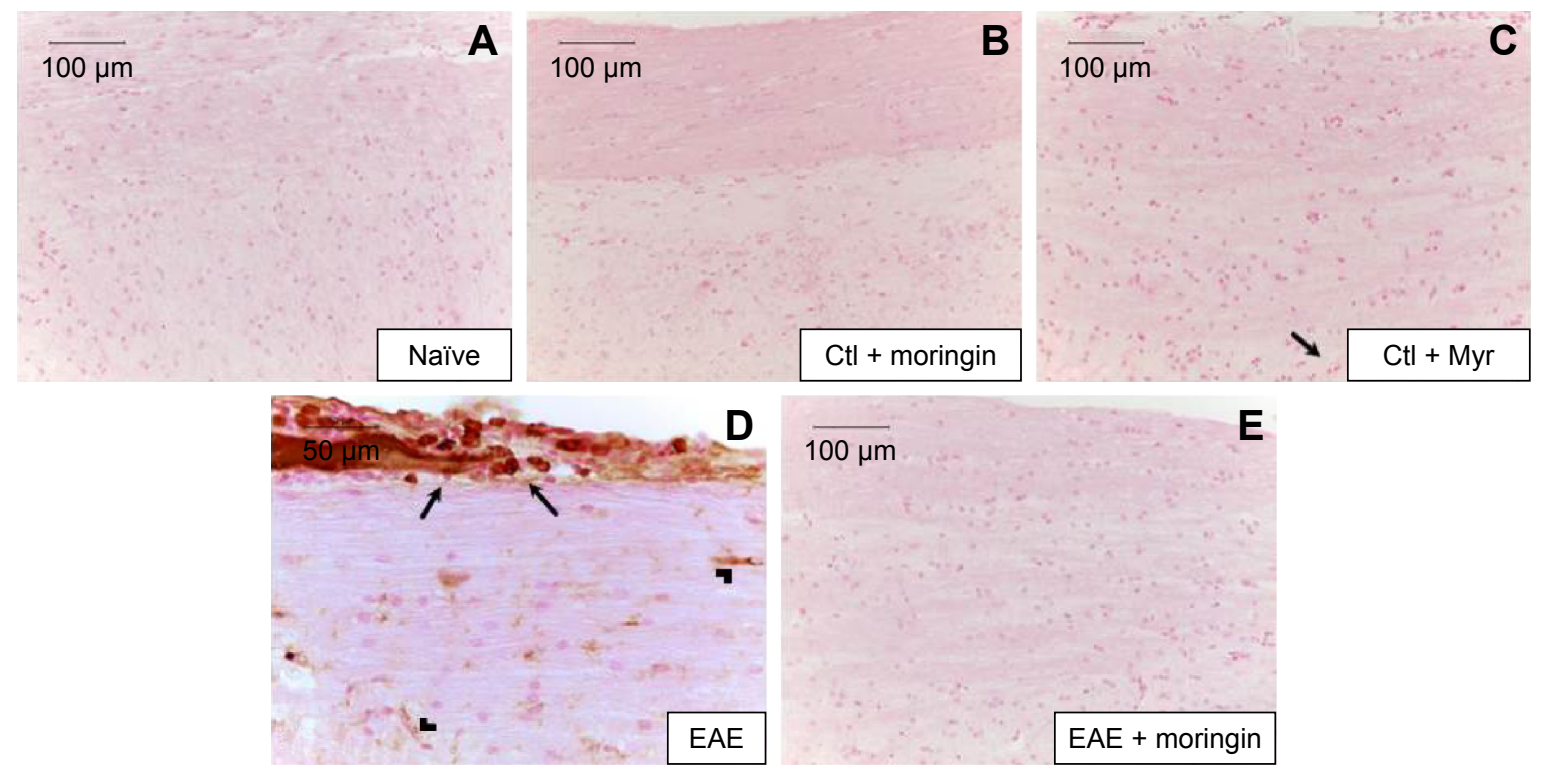

Figure 8 Moringin modulates IL-6 expression in EAE.

Notes: Immunohistochemical evaluation for IL-6 in naïve mice (A), Ctl + moringin (B), Ctl + Myr (C), EAE mice (D), and EAE mice pretreated with moringin (E). All images are representative of three independent experiments. The arrows indicate positive staining for inflammatory cells in vascular endothelium of spinal cord tissues. Abbreviations: EAE, experimental autoimmune encephalomyelitis; Ctl, control. 

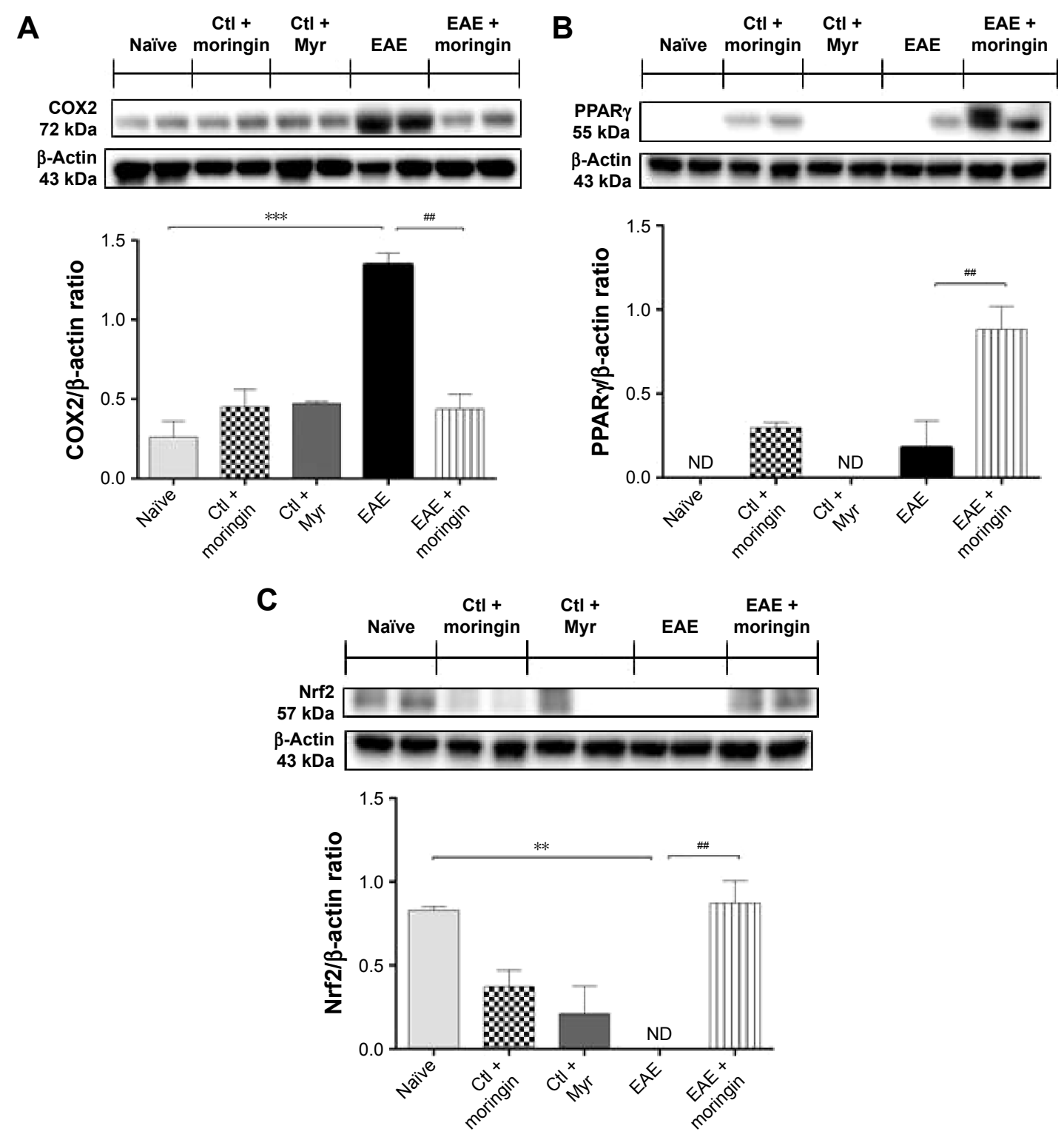

Figure 9 Moringin-modulated inflammatory mediators and Nrf2 activity in EAE.

Notes: Western blot analysis for COX2 (A). Naïve vs EAE, *** $P=0.0005$; EAE vs EAE + moringin, ${ }^{\#} P=0.0012$. Western blot analysis for PPAR $\gamma(\mathbf{B})$. EAE vs EAE + moringin, ${ }^{\# P}=0.0038$. Western blot analysis for Nrf2 (C). Naïve vs $E A E$, $* * P=0.0039$; EAE vs $E A E+$ moringin, $P=0.003$. All Western blot analyses were performed on spinal cord tissues sampled at 28 days from EAE induction. $\beta$-Actin was used as internal control. Blots are representative of three separate and reproducible experiments. Statistical analysis was carried out on three repeated blots performed on separate experiments. Data are expressed as mean \pm SEM.

Abbreviations: EAE, experimental autoimmune encephalomyelitis; Ctl, control; ND, not detectable.

canonical pathway can modulate the immune system by repressing the inflammatory process during MS, the role of the Wnt canonical pathway in regulating remyelination remains controversial. ${ }^{42}$ Some studies have supported the notion that the Wnt $-\beta$-catenin pathway may act as a negative modulator of the remyelination process, via inhibiting oligodendrocyte differentiation and myelin formation. ${ }^{43-45}$ Conversely, results from recent studies suggested that the Wnt canonical pathway may promote remyelination..$^{38,46,47}$

In the present study, we evaluated the involvement of the Wnt- $\beta$-catenin pathway in the etiopathology of an experimental EAE model and also tested a formulation of moringin, obtained from GMG by myrosinase-catalyzed hydrolysis, as a modulator of neuroinflammation via the $\beta$-catenin-PPAR $\gamma$ axis. In accordance with previous studies, ${ }^{12,48}$ our results showed that the canonical Wnt- $\beta$ catenin pathway is inactivated in EAE development. We found that in mice subjected to EAE, cytoplasmic $\beta$-catenin was constantly phosphorylated by increased expression of CK2 $\alpha$ and GSK $3 \beta$, which inhibited nuclear translocation of $\beta$-catenin and consequent activation of Wnt target genes involved in cell survival. The enhanced activity of CK2 $\alpha$ 
and GSK3 $\beta$ was paralleled by Wnt1 suppression. Moreover, upregulation of GSK3 $\beta$ induced the degradation of $\beta$-catenin, which resulted in apoptosis of neurons. Apoptosis was confirmed by significant positive staining for proapoptotic Fas and cleaved caspase 9 in the spinal cord sections of EAE mice. Pretreatment with moringin markedly ameliorated the clinical score induced by EAE.

Interestingly, moringin pretreatment reverted the abnormal Wnt- $\beta$-catenin signaling of EAE mice. We found that moringin reduced levels of CK $2 \alpha$ and GSK $3 \beta$, which in turn increased Wnt1 and nuclear $\beta$-catenin levels. Reduction in GSK3 $\beta$ expression was further supported by the absence of cytoplasmic phosphorylated $\beta$-catenin, which resulted in the attenuation of apoptosis, evidenced by reduction in Fas and cleaved caspase 9. Moreover, we noticed that in the spinal cord of EAE mice, CD4 and FoxP3 levels were elevated, which indicated engagement and infiltration of $\mathrm{T}_{\text {reg }}$ cells in the CNS. MOG-induced activation of $\mathrm{CD}^{+} / \mathrm{Foxp}^{+}$ $\mathrm{T}_{\text {reg }}$ cells have been already demonstrated in EAE mice. ${ }^{49}$ The proinflammatory mediators IL- $1 \beta$, IL-6, and COX2 were

\section{Wnt- $\beta$-catenin OFF}

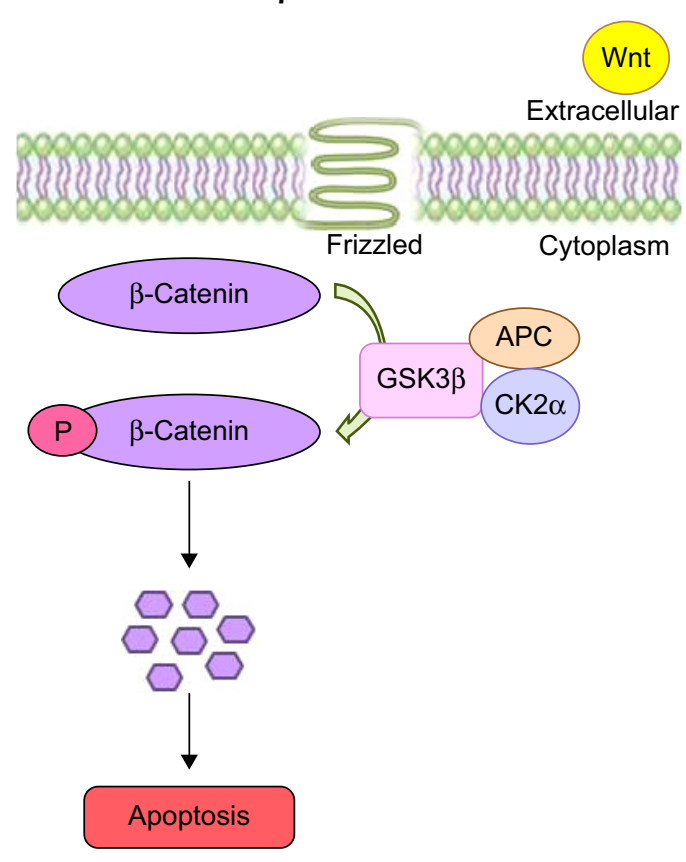

also increased. Moringin repressed EAE-associated $\mathrm{T}_{\text {reg }}$-cell activation by diminishing CD4 and FoxP3 levels. Additionally, moringin decreased IL-1 $\beta$, IL-6, and COX2 levels in EAE mice. Indeed, similar suppression of T-cell response in EAE has been demonstrated by sulforaphane, another widely examined isothiocyanate present in cruciferous vegetables. ${ }^{50,51}$ From our findings, we propose that moringin may control EAE-associated $\mathrm{T}_{\text {reg }}$-cell molecules via Wnt-signaling activation. It is well known that the Wnt-signaling pathway regulates T-cell activation. ${ }^{52,53}$ Increased Wnt1/ $\beta$-catenin levels and decreased GSK3$\beta$ level in moringin-administered EAE mice corroborated our notion, suggesting the active inhibition of MOG-induced T-cell activation via the moringin-mediated Wnt-signaling pathway.

Studies in recent years have demonstrated the beneficial efficacy of PPAR $\gamma$ agonists in the treatment of MS and other neurodegenerative diseases to suppress inflammatory and oxidative stress. ${ }^{54-56}$ Since PPAR $\gamma$ is associated with the Wnt- $\beta$-catenin pathway, ${ }^{18,19}$ we investigated whether moringin could be a potential activator of PPAR $\gamma$ via

\section{Wnt- $\beta$-catenin ON}
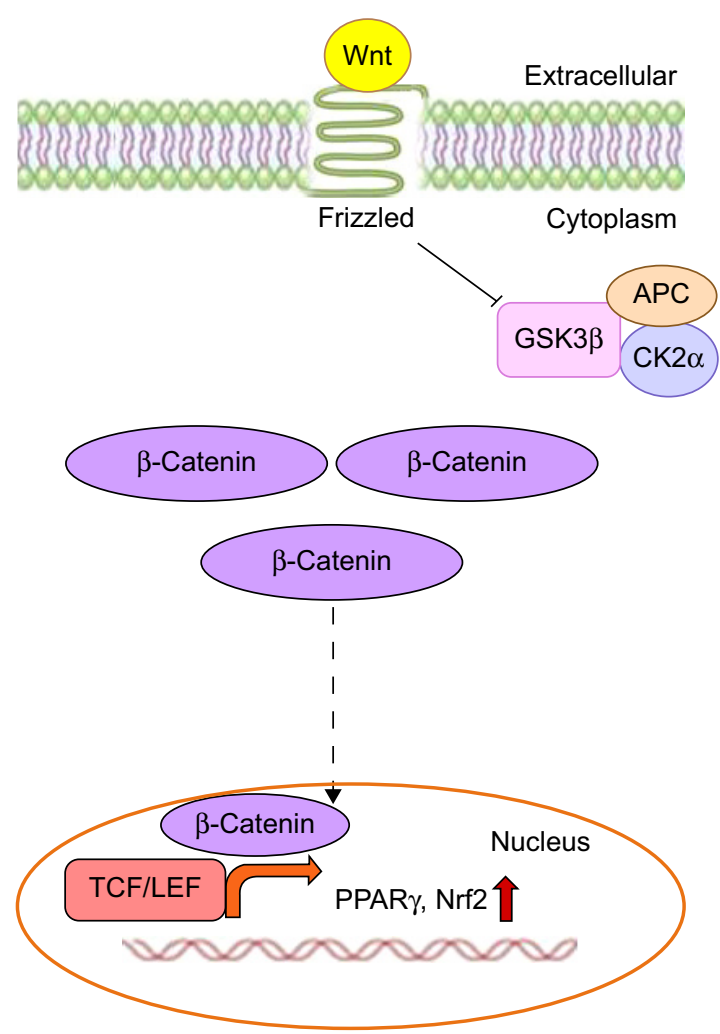

Figure $10 \mathrm{Wnt}-\beta$-catenin canonical pathway.

Notes: In the absence of the Wnt ligand (off), $\beta$-catenin is phosphorylated by the destruction complex formed by Axin, APC, CK2 $\alpha$, and GSK3 $\beta$, leading to $\beta$-catenin degradation and subsequent induction of neuronal cell death. In the presence of the Wnt ligand, the Wnt canonical pathway is activated (on), and $\beta$-catenin is not phosphorylated by the destruction complex formed by Axin, APC, CK $2 \alpha$, and GSK3 $\beta$. Therefore, $\beta$-catenin is free to translocate into the nucleus, where it binds with the TCF/LEF transcription factors and promotes the transcription of Wnt target genes. 
Wnt- $\beta$-catenin signaling. We observed a mild increase in PPAR $\gamma$ levels in EAE mice, which might have resulted from an innate anti-inflammatory response. Interestingly, EAE mice administered with moringin exhibited marked upregulation in PPAR $\gamma$ expression. We assume that the observed reduction of the proinflammatory mediators IL- $1 \beta$, IL-6, and COX2 in moringin-treated EAE mice might be attributed to elevated levels of PPAR $\gamma$.

Moreover, moringin pretreatment augmented antioxidant Nrf2 expression in EAE mice. It has been well documented that isothiocyanates may exert their antioxidative effects by Nrf2 activation. ${ }^{36,57}$ Of note, it is important to emphasize that GSK3 $\beta$ downregulation increases Nrf2 expression. ${ }^{36} \mathrm{We}$ assume that the enhanced expression of Nrf2 might have resulted from the moringin-regulated reduction of GSK3 $\beta$. Our results are in parallel with previous studies, where it has been reported that synthetic sulforaphane, another widely examined isothiocyanate present in cruciferous vegetables, increased the level of Nrf2 by reducing GSK3 $\beta$ expression. ${ }^{58-60}$ Figure 10 shows a graphic representation of $\beta$-catenin signalingmediated PPAR $\gamma$ and Nrf2 regulation in the presence or absence of Wnt.

\section{Conclusion}

Our results demonstrated that in EAE mice, moringin normalizes the aberrant Wnt $-\beta$-catenin pathway and inhibits GSK $3 \beta$. Furthermore, moringin suppresses proinflammatory mediators via PPAR $\gamma$ activation and attenuates apoptosis. We propose that moringin might be a potential PPAR $\gamma$ agonist in the treatment of MS.

\section{Acknowledgment}

This study was supported by Current Research Funds 2014 of IRCCS Centro Neurolesi Bonino-Pulejo, Messina, Italy.

\section{Author contributions}

SG performed the animal experiments and wrote the first draft of the manuscript. SG and TSR performed the biochemical analyses. GRDN and RI conducted the isolation and purification of GMG and myrosinase. EM performed immunohistochemical analysis. PB and EM designed the study. All authors contributed toward data analysis, drafting and critically revising the paper and agree to be accountable for all aspects of the work.

\section{Disclosure}

The authors report no conflicts of interest in this work.

\section{References}

1. Inestrosa NC, Arenas E. Emerging roles of Wnts in the adult nervous system. Nat Rev Neurosci. 2010;11(2):77-86.

2. van Amerongen R, Mikels A, Nusse R. Alternative Wnt signaling is initiated by distinct receptors. Sci Signal. 2008;1(35):re9.

3. Gordon MD, Nusse R. Wnt signaling: multiple pathways, multiple receptors, and multiple transcription factors. J Biol Chem. 2006;281(32): 22429-22433.

4. Kikuchi A, Yamamoto H, Sato A, Matsumoto S. New insights into the mechanism of Wnt signaling pathway activation. Int Rev Cell Mol Biol. 2011;291:21-71.

5. Aberle H, Bauer A, Stappert J, Kispert A, Kemler R. $\beta$-Catenin is a target for the ubiquitin-proteasome pathway. EMBO J. 1997;16(13): 3797-3804.

6. Patapoutian A, Reichardt LF. Roles of Wnt proteins in neural development and maintenance. Curr Opin Neurobiol. 2000;10(3):392-399.

7. Ciani L, Salinas PC. Wnts in the vertebrate nervous system: from patterning to neuronal connectivity. Nat Rev Neurosci. 2005;6(5):351-362.

8. Oliva CA, Vargas JY, Inestrosa NC. Wnts in adult brain: from synaptic plasticity to cognitive deficiencies. Front Cell Neurosci. 2013;7:224.

9. Toledo EM, Colombres M, Inestrosa NC. Wnt signaling in neuroprotection and stem cell differentiation. Prog Neurobiol. 2008;86(3): 281-296.

10. Le Grand JN, Gonzalez-Cano L, Pavlou MA, Schwamborn JC. Neural stem cells in Parkinson's disease: a role for neurogenesis defects in onset and progression. Cell Mol Life Sci. 2015;72(4):773-797.

11. Berwick DC, Harvey K. The importance of Wnt signalling for neurodegeneration in Parkinson's disease. Biochem Soc Trans. 2012;40(5): $1123-1128$.

12. Yuan S, Shi Y, Tang SJ. Wnt signaling in the pathogenesis of multiple sclerosis-associated chronic pain. J Neuroimmune Pharmacol. 2012; 7(4):904-913.

13. Trapp BD, Nave KA. Multiple sclerosis: an immune or neurodegenerative disorder? Аnпи Rev Neurosci. 2008;31:247-269.

14. Goverman J. Autoimmune T cell responses in the central nervous system. Nat Rev Immunol. 2009;9(6):393-407.

15. Weber MS, Menge T, Lehmann-Horn K, et al. Current treatment strategies for multiple sclerosis: efficacy versus neurological adverse effects. Curr Pharm Des. 2012;18(2):209-219.

16. Willson TM, Lambert MH, Kliewer SA. Peroxisome proliferatoractivated receptor gamma and metabolic disease. Anпи Rev Biochem. 2001;70:341-367.

17. Heneka MT, Landreth GE, Hull M. Drug insight: effects mediated by peroxisome proliferator-activated receptor- $\gamma$ in CNS disorders. Nat Clin Pract Neurol. 2007;3(9):496-504.

18. Lecarpentier Y, Claes V, Duthoit G, Hebert JL. Circadian rhythms, $\mathrm{Wnt} / \beta$-catenin pathway and PPAR $\alpha / \gamma$ profiles in diseases with primary or secondary cardiac dysfunction. Front Physiol. 2014;5:429.

19. Sabatino L, Pancione M, Votino C, et al. Emerging role of the $\beta$-catenin-PPAR $\gamma$ axis in the pathogenesis of colorectal cancer. World J Gastroenterol. 2014;20(23):7137-7151.

20. Giacoppo S, Galuppo M, Montaut S, et al. An overview on neuroprotective effects of isothiocyanates for the treatment of neurodegenerative diseases. Fitoterapia. 2015;106:12-21.

21. Galuppo M, Giacoppo S, De Nicola GR, et al. Antiinflammatory activity of glucomoringin isothiocyanate in a mouse model of experimental autoimmune encephalomyelitis. Fitoterapia. 2014;95:160-174.

22. Brunelli D, Tavecchio M, Falcioni C, et al. The isothiocyanate produced from glucomoringin inhibits NF-kB and reduces myeloma growth in nude mice in vivo. Biochem Pharmacol. 2010;79(8):1141-1148.

23. Maldini M, Maksoud SA, Natella F, et al. Moringa oleifera: study of phenolics and glucosinolates by mass spectrometry. J Mass Spectrom. 2014;49(9):900-910.

24. Abdull Razis AF, De Nicola GR, Pagnotta E, Iori R, Ioannides C. 4-Methylsulfanyl-3-butenyl isothiocyanate derived from glucoraphasatin is a potent inducer of rat hepatic phase II enzymes and a potential chemopreventive agent. Arch Toxicol. 2012;86(2):183-194. 
25. Baasanjav-Gerber C, Monien BH, Mewis I, et al. Identification of glucosinolate congeners able to form DNA adducts and to induce mutations upon activation by myrosinase. Mol Nutr Food Res. 2011;55(5): 783-792.

26. Barillari J, Cervellati R, Paolini M, Tatibouet A, Rollin P, Iori R. Isolation of 4-methylthio-3-butenyl glucosinolate from Raphanus sativus sprouts (kaiware daikon) and its redox properties. J Agric Food Chem. 2005;53(26):9890-9896.

27. [No authors listed]. EEC regulation 1864/90, enclosure VIII. Offic J Eur Commun. 1990;L170:27-34.

28. Giacoppo S, Galuppo M, De Nicola GR, Iori R, Bramanti P, Mazzon E. $4(\alpha-1$-rhamnosyloxy)-benzyl isothiocyanate, a bioactive phytochemical that attenuates secondary damage in an experimental model of spinal cord injury. Bioorg Med Chem. 2015;23(1):80-88.

29. Pessina A, Thomas RM, Palmieri S, Luisi PL. An improved method for the purification of myrosinase and its physicochemical characterization. Arch Biochem Biophys. 1990;280(2):383-389.

30. Giacoppo S, Galuppo M, De Nicola GR, Iori R, Bramanti P, Mazzon E. Tuscan black kale sprout extract bioactivated with myrosinase: a novel natural product for neuroprotection by inflammatory and oxidative response during cerebral ischemia/reperfusion injury in rat. $B M C$ Complement Altern Med. 2015;15:397.

31. Galuppo M, Giacoppo S, Iori R, De Nicola GR, Bramanti P, Mazzon E. Administration of 4-( $\alpha$-L-rhamnosyloxy)-benzyl isothiocyanate delays disease phenotype in SOD1 ${ }^{\mathrm{G} 93 \mathrm{~A}}$ rats: a transgenic model of amyotrophic lateral sclerosis. Biomed Res Int. 2015;2015:259417.

32. Paschalidis N, Iqbal AJ, Maione F, et al. Modulation of experimental autoimmune encephalomyelitis by endogenous annexin A1.J Neuroinflammation. 2009;6:33.

33. Rodrigues DH, Vilela MC, Barcelos LS, Pinho V, Teixeira MM, Teixeira AL. Absence of PI3K $\gamma$ leads to increased leukocyte apoptosis and diminished severity of experimental autoimmune encephalomyelitis. J Neuroimmunol. 2010;222(1-2):90-94.

34. Constantinescu CS, Farooqi N, O'Brien K, Gran B. Experimental autoimmune encephalomyelitis (EAE) as a model for multiple sclerosis (MS). Br J Pharmacol. 2011;164(4):1079-1106.

35. Hu R, Hebbar V, Kim BR, et al. In vivo pharmacokinetics and regulation of gene expression profiles by isothiocyanate sulforaphane in the rat. J Pharmacol Exp Ther. 2004;310(1):263-271.

36. Dinkova-Kostova AT, Holtzclaw WD, Cole RN, et al. Direct evidence that sulfhydryl groups of Keap1 are the sensors regulating induction of phase 2 enzymes that protect against carcinogens and oxidants. Proc Natl Acad Sci U S A. 2002;99(18):11908-11913.

37. Noseworthy JH, Lucchinetti C, Rodriguez M, Weinshenker BG. Multiple sclerosis. N Engl J Med. 2000;343(13):938-952.

38. Marchetti B, Pluchino S. Wnt your brain be inflamed? Yes, it Wnt! Trends Mol Med. 2013;19(3):144-156.

39. Kim H, Won S, Hwang DY, et al. Downregulation of Wnt/ $\beta$-catenin signaling causes degeneration of hippocampal neurons in vivo. $\mathrm{Neu}$ robiol Aging. 2011;32(12):2316.e1-e15.

40. Halleskog C, Mulder J, Dahlström J, et al. Wnt signaling in activated microglia is proinflammatory. Glia. 2011;59(1):119-131.

41. L'Episcopo F, Tirolo C, Testa N, et al. Reactive astrocytes and $\mathrm{Wnt} / \beta$-catenin signaling link nigrostriatal injury to repair in 1-methyl4-phenyl-1,2,3,6-tetrahydropyridine model of Parkinson's disease. Neurobiol Dis. 2011;41(2):508-527.
42. Xie C, Li Z, Zhang GX, Guan Y. Wnt signaling in remyelination in multiple sclerosis: friend or foe? Mol Neurobiol. 2014;49(3):1117-1125.

43. Fancy SP, Baranzini SE, Zhao C, et al. Dysregulation of the Wnt pathway inhibits timely myelination and remyelination in the mammalian CNS. Genes Dev. 2009;23(13):1571-1585.

44. Shimizu T, Kagawa T, Wada T, Muroyama Y, Takada S, Ikenaka K. Wnt signaling controls the timing of oligodendrocyte development in the spinal cord. Dev Biol. 2005;282(2):397-410.

45. Gaesser JM, Fyffe-Maricich SL. Intracellular signaling pathway regulation of myelination and remyelination in the CNS. Exp Neurol. Epub 2016 Mar 5.

46. Hanafy KA, Sloane JA. Regulation of remyelination in multiple sclerosis. FEBS Lett. 2011;585(23):3821-3828

47. Ye F, Chen Y, Hoang T, et al. HDAC1 and HDAC2 regulate oligodendrocyte differentiation by disrupting the $\beta$-catenin-TCF interaction. Nat Neurosci. 2009;12(7):829-838.

48. Swafford D, Manicassamy S. Wnt signaling in dendritic cells: its role in regulation of immunity and tolerance. Discov Med. 2015;19(105): 303-310.

49. Zorzella-Pezavento SF, Chiuso-Minicucci F, Franca TG, et al. Persistent inflammation in the CNS during chronic EAE despite local absence of IL-17 production. Mediators Inflamm. 2013;2013:519627.

50. Geisel J, Brück J, Glocova I, et al. Sulforaphane protects from T cellmediated autoimmune disease by inhibition of IL-23 and IL-12 in dendritic cells. J Immunol. 2014;192(8):3530-3539.

51. Li B, Cui W, Liu J, et al. Sulforaphane ameliorates the development of experimental autoimmune encephalomyelitis by antagonizing oxidative stress and Th17-related inflammation in mice. Exp Neurol. 2013;250: 239-249.

52. van Loosdregt J, Fleskens V, Tiemessen MM, et al. Canonical Wnt signaling negatively modulates regulatory $\mathrm{T}$ cell function. Immunity. 2013;39(2):298-310

53. Staal FJ, Luis TC, Tiemessen MM. Wnt signalling in the immune system: Wnt is spreading its wings. Nat Rev Immunol. 2008;8(8):581-593.

54. Drew PD, Xu J, Racke MK. PPAR- $\gamma$ : therapeutic potential for multiple sclerosis. PPAR Res. 2008;2008:627463.

55. Kaundal RK, Sharma SS. Peroxisome proliferator-activated receptor $\gamma$ agonists as neuroprotective agents. Drug News Perspect. 2010;23(4): 241-256.

56. Mrak RE, Landreth GE. PPAR $\gamma$, neuroinflammation, and disease. J Neuroinflammation. 2004;1(1):5.

57. Ernst IM, Palani K, Esatbeyoglu T, Schwarz K, Rimbach G. Synthesis and Nrf2-inducing activity of the isothiocyanates iberverin, iberin and cheirolin. Pharmacol Res. 2013;70(1):155-162.

58. Rada P, Rojo AI, Evrard-Todeschi N, et al. Structural and functional characterization of Nrf2 degradation by the glycogen synthase kinase 3/ $\beta$-TrCP axis. Mol Cell Biol. 2012;32(17):3486-3499.

59. Shang G, Tang X, Gao P, et al. Sulforaphane attenuation of experimental diabetic nephropathy involves GSK-3 $\beta / \mathrm{Fyn} / \mathrm{Nrf} 2$ signaling pathway. J Nutr Biochem. 2015;26(6):596-606.

60. Rojo AI, Rada P, Egea J, Rosa AO, Lopez MG, Cuadrado A. Functional interference between glycogen synthase kinase- $3 \beta$ and the transcription factor Nrf2 in protection against kainate-induced hippocampal cell death. Mol Cell Neurosci. 2008;39(1):125-132.
Drug Design, Development and Therapy

\section{Publish your work in this journal}

Drug Design, Development and Therapy is an international, peerreviewed open-access journal that spans the spectrum of drug design and development through to clinical applications. Clinical outcomes, patient safety, and programs for the development and effective, safe, and sustained use of medicines are the features of the journal, which
Dovepress

has also been accepted for indexing on PubMed Central. The manuscript management system is completely online and includes a very quick and fair peer-review system, which is all easy to use. Visit http://www.dovepress.com/testimonials.php to read real quotes from published authors. 